\title{
UM POUCO MAIS DA HISTÓRIA DA EDUCAÇÃO DOS SURDOS, SEGUNDO FERDINAND BERTHIER
}

\section{Lilian Cristine Ribeiro Nascimento}

\section{RESUMO}

Este artigo traz trechos da biografia do abade l'Epée, escrita por um professor surdo do Instituto para surdos de Paris, Ferdinand Berthier, em 1840. Apesar de enaltecer a figura do abade, criador da primeira escola para surdos na França, Berthier tece críticas ao método de l'Epée, uma vez que, segundo ele, em nome do ensino da escrita correta eram realizadas deformações na linguagem de sinais, modificações que acabavam por torná-la estranha aos próprios surdos. Apesar de escrito há dois séculos o texto de Berthier traz discussões que ainda hoje estão presentes entre os educadores, nas quais o tema central é a língua a que os surdos devem ser expostos no processo educacional. A polêmica língua de sinais versus língua oral apresentava-se, naquela época, como hoje, como o centro das discussões na educação dos surdos.

\author{
PALAVRAS - CHAVE
}

Educação de surdos; Língua de sinais; Ferdinand Berthier

\section{A LITTLE BIT MORE ABOUT THE DEAF EDUCATION, ACCORDING TO FERDINAND BERTHIER}

\section{ABSTRACT}

This article features extracts from the biography of the abbot L'Epée, written by a deaf professor from the Deaf Institute of Paris, Ferdinand Berthier, in 1840. Despite glorifying the abbot, who was the creator of the first deaf school in France, Berthier voiced criticism of the L'Epée method for generating deformities in the sign language for the sake of teaching correct writing; such changes made the language foreign to the deaf people themselves. Although written two centuries ago, Berthier's work provokes discussions that to this day are still present among educators, discussions where the central theme is the language to which the deaf are exposed in the learning process. The controversy over sign language versus oral language played as central a role in those days as it does today in discussions about deaf education.

\section{KEYWORDS}

Deaf education; Sign language; Ferdinand Berthier 
A história da educação dos surdos tem sido marcada por uma discussão polêmica sobre qual a melhor maneira de educá-los. Essa discussão traz como tema a questão lingüística, colocando em conflito dois blocos de pensamentos: aquele que defende o ensino da língua oral para os surdos como única forma de inseri-los na comunidade ouvinte e aquele que defende a língua de sinais, própria da comunidade surda, como meio lingüístico pelo qual deve-se desenvolver sua educação.

Apesar de atual, tal discussão tem seu princípio concomitante ao início das práticas educacionais para os surdos.

Neste artigo, trago alguns trechos do texto de Ferdinand Berthier, escrito em 1840, e tenho como objetivo evidenciar como a discussão sobre a língua a ser utilizada na educação dos surdos (língua de sinais ou língua oral) é antiga e como esta se prolonga no tempo, trazendo embutidas idéias e princípios que permanecem ainda hoje em nosso cotidiano.

Ferdinand Berthier era surdo congênito e nasceu em 1803 na cidade de Louhans, na França. Foi considerado por Laurent Clerc, professor também surdo, o mais brilhante aluno do Instituto para Surdos de Paris. Berthier entrou para o Instituto aos 8 anos, onde formou-se, e trabalhou posteriormente como professor. Foi também uma figura importante na comunidade literária de seu tempo.

Berthier escreveu vários livros e numerosos artigos sobre o surdo, sua educação e seus direitos legais. Criou a primeira organização social para o surdo em Paris e foi a primeira pessoa surda a receber o prêmio Legião de Honra. Berthier escreveu a biografia de l'Epée (1712-1789) em um artigo denominado "O surdo antes e depois do abade l'Epée", a pedido dos membros da Sociedade para as Ciências Morais, Letras e Artes de Seine-et-Oise, que lhe propuseram " investigar a condição social do surdo antes do abade de l'Epée, e que meios ele empregou para sua educação; usar essas duas investigações para conseguir uma exata apreciação da realização de l'Epée como fundador de uma nova instituição e como benfeitor da humanidade"(BERTHIER, 1984, p.163). Esse artigo seria usado como argumento para oferecer a l'Epée um prêmio dado anualmente a uma pessoa ilustre da sociedade francesa.

Com este intuito, Berthier relatou a história da educação dos surdos, iniciando por professores anteriores a l'Epée e, posteriormente, assinalando as inovações introduzidas pelo abade. Berthier era grande admirador de l'Epée e seu texto é repleto de elogios. Apesar disso, não se isenta de criticá-lo em alguns aspectos como, por exemplo, na forma como ele ensinava aos surdos a gramática do francês.

(C) ETD - Educação Temática Digital, Campinas, v.7, n.2, p.255-265, jun. 2006 - ISSN: 1676-2592. 


\section{DOSSIÊ \\ Grupo de Estudos e Subjetividade}

Inicia a história na antigüidade, relatando as conhecidas atrocidades realizadas contra os surdos pelos espartanos, que condenavam a criança a sofrer a mesma morte reservada ao retardado ou ao deformado: "A infortunada criança era prontamente asfixiada ou tinha sua garganta cortada ou era lançada de um precipício para dentro das ondas. Era uma traição poupar uma criatura de quem a nação nada poderia esperar" (BERTHIER, 1984, p.165).

Relata que no sistema romano os surdos eram privados de seus direitos legais e, entre os egípcios e persas, o destino dos surdos era um assunto de interesse religioso, pois suas debilidades eram consideradas um sinal visível dos deuses. Berthier afirma que somente a religião cristã trouxe aos surdos sua dignidade e os salvou do exílio em que se encontravam.

Até esse ponto sua narrativa da história dos surdos não apresenta nenhuma novidade, mas ao iniciar o relato da educação dos surdos a partir da idade moderna, nos surpreende com a afirmação de que é um erro considerar Pedro Ponce de León (1520 - 1584) o primeiro professor de surdos:

\footnotetext{
Hoje é amplamente reconhecido que toda a contribuição de Ponce foi meramente colocar os princípios da educação para surdos em um patamar mais amplo do que seus predecessores fizeram.

Antes de Ponce, muitas tentativas isoladas de instrução tinham sido feitas, com nível de sucesso variável, tanto na França quanto no exterior. Em 1578, Joachim Pascha treinou dois de seus próprios filhos surdos, mas suas tentativas não obtiveram reconhecimento público. Jérôme Cardan, uma das pessoas mais inteligentes de seu tempo, e quem talvez tenha mais profundamente revigorado a escola filosófica de seu século, buscou demonstrar que a educação do surdo não era uma impossibilidade; ele não parou aí e manteve um relatório escrito sobre alguns importantes pontos sobre este especial tipo de ensino (BERTHIER, 1984, p.169).
}

Ainda tratando de professores espanhóis, Berthier nos revela sua indignação ao ver Juan Pablo Bonet (1579 - 1629), autor do livro "Arte para enseñar a hablar a los mudos", creditar a si a descoberta de como ensinar o surdo a falar. Segundo Berthier, tal crédito poderia ser reivindicado por seu rival Ramirez de Carrion, que era surdo congênito e teve sucesso, no julgamento dos críticos de seu tempo, em um experimento com Emmanuel Philibert, o príncipe surdo de Carignan. "Seu livro, publicado nove anos depois do de Bonet, recebeu o título Maravillas de naturaleza, em que se contienen dos mil secretos de cosas naturales, 1629”. (BERTHIER, 1984, p. 170).

Berthier acrescenta à história outros importantes nomes de professores de surdos, tais como o inglês John Wallis (1616 - 1703), professor de Oxford, primeiro inglês a dedicar-se à educação de surdos. Sobre ele, o autor salienta:

Embora seu trabalho sobre articulação obtivesse total sucesso e seu Tratado sobre o Discurso e a Formação de Sons (Grammatica Linguae Anglicanae) tenha recebido a aprovação dos mais ilustres acadêmicos, ele logo percebeu que os recursos para as pessoas surdas sob seus cuidados 
eram muito escassos se comparados com aqueles contidos na linguagem de sinais. Em sua carta ao Dr. Beverly, no terceiro volume dos trabalhos matemáticos de Wallis, (Transações filosóficas de Londres, 1698), ele escreve: E este (treino de articulação) é de fato o menor trabalho de dois (embora visto como o mais extraordinário). Mas um sem o outro seria de pouco uso. Pois pronunciar palavras simplesmente como um papagaio, sem saber o que elas significam, não nos traria benefício nenhum (BERTHIER,1984, p.170).

Apesar de ter reconhecido a importância dos gestos, Wallis é criticado por Berthier por considerar sinais como sendo meramente as letras do alfabeto ou movimentos dos dedos.

Todos os outros professores ingleses - John Bulwer, William Holder, Digby e Gregory - tinham como objetivo ensinar por meio da fala. Entre os professores holandeses, cita Van Helmont e o médico suíço Conrad Amman, que viveu em Amsterdã. Ambos se empenharam em ensinar o surdo a falar. Mais do que isso, Van Helmont acreditava ser importante ensinar os surdos a falar em hebreu, pois era a única língua que possibilitaria uma comunicação com Deus. Como material de suporte a seu projeto, fez uma descrição do mecanismo do aparato vocal, usando o hebreu para pronunciação.

Dentre os vários professores alemães citados, destaque especial é dado a Samuel Heinicke (1723 - 1790), que também pregava a importância do ensino da fala ao surdo. Contemporâneo de l'Epée, foi, como o português Pereire, um dos maiores rivais de l'Epée. A rivalidade desses três professores contemporâneos, de nacionalidades diferentes, centrava-se num debate que contrapunha, como hoje, a oralidade versus a gestualidade na educação do surdo.

É interessante observar que a história da educação dos surdos traz informações inovadoras quando narrada por um surdo. Através desse relato, vemos que muitos desses homens aclamados pela história como heróis são por ele considerados plagiadores e outras vezes charlatães.

Para Berthier, l'Epée foi o primeiro a livrar o surdo de sua solidão, como refere nesta passagem:

Até então, como eu já havia explicado, todos os educadores de surdos interpretavam o princípio que "nossa mente não contém nada que não chegou lá através dos sentidos" como se seu único trabalho fosse dar a estes desafortunados o uso mecânico da fala. Ao contrário, l'Epée foi o primeiro a vislumbrar na linguagem mímica ainda imperfeita deles, meios mais seguros e simples de comunicação e uma mais direta e clara tradução de pensamento. E ele fez com que seus tesouros escondidos florescessem - verdade, flexibilidade, a riqueza de um idioma que pertence a todas as nações, de fato, a toda a humanidade, um idioma que admiravelmente resolve o problema de uma linguagem universal a qual os acadêmicos em toda parte têm buscado por séculos em vão. A partir do simples argumento que os surdos podem ser instruídos com o auxílio de gestos da maneira como instruímos outras pessoas usando os sons da voz, e que ambos os grupos podem aprender linguagem escrita, o incansável l'Epée criou um novo mundo, toda uma geração (BERTHIER,1984, p.179).

Vê-se que Berthier classificava sua própria língua como imperfeita. Tal afirmação parece ser um efeito da fala dos filósofos e educadores da época, que assim a consideravam. Esse foi o argumento 
de l'Epée para criar os sinais metódicos que acrescentavam à língua de sinais elementos da gramática da língua francesa. O mesmo se pode dizer do conceito de "linguagem universal", idéia amplamente difundida pelos filósofos iluministas. Acreditava-se na existência de uma língua primeira do homem, anterior ao hebraico, que se supunha ser a linguagem de ação, da qual teriam se originado todas as outras línguas.

Era comum, naquela época, os professores de surdos realizarem demonstrações públicas de seus feitos aos reis, filósofos, autoridades e curiosos. Em uma dessas demonstrações de l'Epée a Linguet, importante filósofo da época, podemos entender como l'Epée adaptou a linguagem de sinais dos surdos à gramática do francês, para ensiná-los a escrever corretamente. No exemplo a seguir l'Epée procura demonstrar a Linguet os recursos utilizados para ditar aos surdos a palavra "ininteligibilidade":

Eu necessito de apenas cinco sinais expressos em um instante, como o senhor mesmo viu. $O$ primeiro expressa a ação interna; o segundo, a ação de uma mente lendo internamente, isto é, uma que entenda o que está sendo proposto; o terceiro diz que este estado mental é possível. Isto não reproduz a palavra "inteligível"? E um quarto sinal, que converte este adjetivo em uma qualidade abstrata, não produz a palavra "inteligibilidade"? Finalmente, um quinto sinal adicionando negação nos dá a palavra completa "ininteligibillidade" (L'EPÉE apud BERTHIER,1984, p.197).

Como se vê, a palavra foi decomposta em cinco sinais, de forma que o surdo a escrevesse corretamente. Berthier critica o abade l'Epée neste ponto, dizendo ser desnecessário tal recurso, pois bastava observar como seus alunos (de Berthier) escreviam corretamente sem necessidade de tantos artifícios.

O autor faz sua argumentação a favor da linguagem dos gestos na educação dos surdos, que aparece no texto com diversas nomenclaturas: "mímica", "linguagem dos gestos", "linguagem de ação" e "sinais".

Para tecer sua argumentação a favor dos sinais, traz citações de outros autores, principalmente aqueles que atacavam o método de l'Epée, como podemos ver a seguir:

Durante muito tempo foi universalmente aceita a opinião de que a ausência da fala tornava
impossível a aquisição de idéias abstratas e menos possível ainda o conhecimento de verdades
da mais alta ordem. Para a vergonha de nossos tempos, esta opinião está ainda tão
profundamente enraizada que as massas tiveram uma recepção impassível às tentativas ora
mais, ora menos bem-sucedidas, de Pedro de Ponce e Bonet, na Espanha, de Gregory e Wallis,
na Inglaterra, de Amman, na Holanda, de Pereire e do abade Deschamps, na França
(BERTHIER,1984, p.168).

(C) ETD - Educação Temática Digital, Campinas, v.7, n.2, p.255-265, jun. 2006 - ISSN: 1676-2592. 


\section{DOSSIÊ \\ Grupo de Estudos e Subjetividade}

A respeito do trabalho de Deschamps, autor do "Curso Elementar de Educação do Surdo", Berthier afirma que seu método era meramente uma aplicação mais ou menos feliz dos métodos de seus antecessores. Deschamps criticava o método de l'Epée pois acreditava que, sendo os alunos surdos também inclinados a pronunciar palavras, elas deveriam lhes ser ensinadas de forma que pudessem ser utilizadas como por uma criança normal.

Sobre esse argumento, Berthier comenta que o erro de Deschamps era dedicar a primeira fase do ensino apenas à pronúncia e relegar a mímica para o final. Ele afirma:

Em minha opinião, o procedimento inverso seria mais razoável, pois a instrução de uma pessoa surda através da articulação não será semelhante à de um papagaio, se a mímica não for colocada em prática? Mas este último método pode ser convenientemente deixado de lado somente se nós estivermos certos de que a educação do aluno esteja suficientemente avançada para que ele possa entender o significado de palavras não familiares. (BERTHIER,1984, p.178).

Berthier narra as rivalidades que l'Epée teve que enfrentar para provar que seu método era adequado para a educação dos surdos e para fazer com que os sinais fossem aceitos:

Certamente esse grande trabalho de reconstrução não foi realizado sem fortes ataques pelos teólogos, filósofos, acadêmicos de todos os países que alegavam que sinais representativos não ajudariam a alcançar idéias metafísicas dentro da mente da pessoa surda. L'Epée pode provar para seus oponentes que uma idéia não é mais intimamente confinada aos sons da fala do que a palavras escritas, e que a única coisa requerida para ativar a idéia no cérebro é uma intermediação que estimule os olhos ou indique o significado da palavra (BERTHIER,1984, p.181).

Berthier tinha a clareza de que a linguagem de sinais constituía um verdadeiro idioma, como podemos notar na afirmação do autor:

Tudo que eu posso dizer sobre a linguagem de sinais é que, ainda hoje, poucas das pessoas que falam têm uma precisa idéia do que consistem esta linguagem e sua genialidade. Muito menos simples do que se costuma supor, ela tem um pequeno número de ingredientes em um infinito número de combinações e isto é avivado pelo jogo de fisionomias. Ela tem tudo que é necessário para representar todas as idéias que povoam a mente e todos os sentimentos que provocam o coração. Em resumo, ela sozinha combina a simplicidade e a universalidade da matemática, a mais perfeita de todas as ciências, com seus dez numerais (BERTHIER,1984, p.175).

Esse mesmo sentido - o de afirmar que os sinais constituíam uma língua - encontramos no texto de outro professor surdo, Desloges, escrito um pouco antes ao de Berthier, em 1779:

(C) ETD - Educação Temática Digital, Campinas, v.7, n.2, p.255-265, jun. 2006 - ISSN: 1676-2592. 


\section{DOSSIÊ \\ Grupo de Estudos e Subjetividade}

(...) certa vez l'Epée concebeu o nobre projeto de devotar-se à educação do surdo; ele sabiamente observou que eles possuíam uma linguagem natural para se comunicarem entre si. Como essa linguagem não era outra senão a de sinais, ele supôs que, se ele se empenhasse em compreendê-la, o triunfo de seu empreendimento seria assegurado. Esse discernimento foi recompensado com sucesso. Então o abade de l'Epée não foi o inventor ou o criador dessa linguagem; pelo contrário, ele a aprendeu com o surdo; ele somente reparou o que encontrou incompleto nela; ele a ampliou e lhe deu regras metódicas (DESLOGES, 1984, p. 34).

Apesar do reconhecimento dessa linguagem, Desloges, assim como Berthier, tiveram os próprios discursos afetados pela concepção dominante na época - e ainda hoje -, de que sua língua é incompleta. No discurso desses surdos verifica-se a marca da concepção iluminista sobre a transparência dos sinais: "(...) L'Epée foi o primeiro a vislumbrar na linguagem mímica ainda imperfeita deles, meios mais seguros e simples de comunicação e uma mais direta e clara tradução de pensamento" (BERTHIER, 1984, p.179).

Mesmo defendendo os sinais na educação dos surdos, Berthier não negligencia a possibilidade da aprendizagem da fala e da leitura labial pelos surdos, mas salienta que estas deveriam ser aprendidas apenas posteriormente, e por aqueles que demonstrassem aptidão para elas. Afirma ser um erro forçar a sua aprendizagem.

Primeiramente, nós devemos notar que a fala, assim como a leitura labial, é meramente um acessório, (...) apropriado somente para treinamento de alunos que se considere ter aptidão para isso, tomando o cuidado de não impor isto a todos ou, acima de tudo, não forçar isto a alunos com intransponível aversão à tarefa. Se, entretanto, como afirmam certos instrutores, a educação de surdos se resume à articulação, à leitura labial ou até mesmo ao processo de soletrar palavras através dos dedos, nós poderíamos apenas começar a ensiná-los um assunto, aritmética, por exemplo, quando eles tivessem feito progresso suficiente no estudo da língua falada para entender as explicações dadas oralmente. Digam-me agora, quantos estudantes do último ano podem realizar uma prova aritmética somente com a ajuda da escrita? Provavelmente nenhum sequer. Então, o que aconteceria se nós tivéssemos que recorrer à fala artificial? A leitura labial é meramente um tipo de adivinhação na qual o significado das sílabas visíveis ajuda alguém a decifrar, acrescentar ou adivinhar o que permanece fora do alcance da visão. Longe de conduzir diretamente à interpretação do pensamento, a leitura labial constantemente precisa ser interpretada pelo pensamento. Ela pode servir como um dispositivo de memória para frases previsíveis na conversação cotidiana; mas ela nunca será um meio regular de instrução ou de elaboração cumulativa de idéias. Em vão nós combatemos a força da verdade; nós acabamos abrindo passagem à certeza evidente e descartando um promissor sistema de instrução que nos ameaça com uma regressão aos primórdios (BERTHIER,1984, p.190 - 191).

Suas recomendações soam tão atuais aos educadores que não parecem ter sido feitas há dois séculos:

A experiência sugere que nós precisamos tomar o maior cuidado possível na seleção de um professor para o surdo. Conforme sugeri, as mais importantes qualificações são um perfeito conhecimento e a extensa prática da linguagem da ação. Infelizmente, deve ser dito, as pessoas às quais foram confiadas o destino do Instituto Real de Paris nem sempre compreenderam isso. A posição dos instrutores de surdos tem às vezes sido injusta e também freqüentemente tem 


\section{DOSSIÊ \\ Grupo de Estudos e Subjetividade}

sido esquecido que, com igual justiça, eles talvez tivessem o direito a igual consideração (BERTHIER,1984 p.190).

Berthier salienta também a importância da escrita para o surdo:

A influência da linguagem de sinais no desenvolvimento intelectual da pessoa surda - tão grande como a influência dos sons da fala tem sobre a mente de uma criança ouvinte - não revela que pode ser fornecida uma grande quantidade de conhecimento sem a ajuda de linguagem escrita e que este conhecimento pode mais tarde servir para interpretar a linguagem falada? Posteriormente, a linguagem escrita registra idéias adquiridas, as coloca em categorias metódicas, e as torna mais precisas, aliviando assim o peso que elas exercem na memória e fornecendo uma nova energia à compreensão, ou pelo menos, fornecendo a ela um uso mais livre de toda a energia a seu dispor (BERTHIER,1984, p.188).

Berthier elogia l'Epée não só por ter aberto a possibilidade do uso dos sinais na educação, mas por sua extrema humildade e abnegação. Ele nos conta como l'Epée abriu mão de sua herança e até mesmo de suas necessidades básicas em favor dos surdos. L'Epée é aclamado com todas as glórias, é chamado por ele de "São Vicente de Paula dos surdos".

Todavia, Berthier tece críticas a l'Epée, assim como a Sicard (sucessor de l'Epée) por aterem os sinais mais às palavras do que às idéias, ou seja, ambos estavam mais preocupados em transcrever os sinais para a escrita do francês. Com os sinais metódicos um surdo poderia escrever palavras corretamente, mesmo sem compreender seu significado. Para ele, um sucessor que conseguiu superar esses erros foi Bébian (1789 - 1834). Bébian, embora ouvinte, havia estudado e convivido com os surdos desde criança no Instituto de Paris. Nessa condição pôde perceber que a linguagem de sinais usada pelos surdos não era a mesma criada por l'Epée. Segundo ele, "o surdo que podia anotar qualquer coisa ditada a ele por sinais, não podia expressar espontaneamente mesmo seus pensamentos mais simples" (BÉBIAN, 1984, p.140).

Para Berthier, Bébian era um verdadeiro conhecedor da língua dos surdos e portanto, "eliminou do currículo toda bagagem intelectual excessiva que simplesmente atrasava o progresso dos estudantes e trouxe de volta ao ensino a simplicidade e a verdade" (BERTHIER, 1984, p.185).

Após a leitura dessa bela narrativa, posso concluir que o texto de Berthier, além de um relato exaltado à vida do abade l'Epée, é uma instigante defesa da língua de sinais na educação e na vida das pessoas surdas. Ele nos mostra que a discussão sobre o uso da gestualidade versus o uso da oralidade é muito antiga. Sobre a dificuldade dos educadores em aceitar os sinais, ele questiona: "Qual é a fonte desta tenacidade que resiste tanto à voz da razão quanto às lições da experiência? Eu não posso e não devo acusar somente a antiga predileção de dar à fala o papel principal no desenvolvimento mental. 


\section{DOSSIÊ \\ Grupo de Estudos e Subjetividade}

Isto tem sido e será por muito tempo o maior obstáculo ao progresso na educação do surdo" (BERTHIER, 1984, p.191).

A tenacidade da resistência dos educadores à língua de sinais, que Berthier denunciava dois séculos atrás, pode ainda hoje ser observada em nosso meio. O autor acertou ao prever que este seria um obstáculo para a educação dos surdos ainda por muito tempo. Ainda hoje tal discussão se faz presente, motivada, principalmente, pela proposta de inclusão dos surdos em escolas regulares, espaço onde sua língua é excluída em prol da "suposta" inserção social. No entanto, a luta dos movimentos sociais dos surdos sinalizadores aos poucos vem abrindo espaço para que sua língua seja respeitada e acima de tudo compreendida como uma língua verdadeira, com a qual sua educação pode se concretizar; com a qual podem se comunicar, fazer planos e sonhar; e com a qual podem, acima de tudo, ter acesso a informações importantes na sociedade em que vivem, uma vez que esta lhe permite ser tornar leitor da modalidade escrita da língua majoritária de sua comunidade.

A resistência dos sujeitos surdos à imposição de oralização a que foram (e são) submetidos por muito tempo pode ser metaforizada na fábula "A águia e a galinha", com a qual finalizo este artigo, deixando-a para reflexão. A escolha deste texto não foi feita ao acaso, e sim após um episódio por mim vivenciado na clínica fonoaudiológica. Ao ler esta fábula com um adolescente surdo, o mesmo fez uma analogia com sua experiência, relatando: "Essa é como a história da minha vida, isso também aconteceu comigo. Só aprendi a voar quando conheci a língua de sinais aos 8 anos"'1 . Segue, então, a fábula, aqui narrada por Leonardo Boff (1997, p. 30-34):

“Era uma vez um camponês que foi à floresta vizinha apanhar um pássaro para mantê-lo cativo
em sua casa. Conseguiu pegar um filhote de águia. Colocou-o no galinheiro junto com as
galinhas. Comia milho e ração própria para galinhas. Embora a águia fosse o rei / rainha de
todos os pássaros.
Depois de cinco anos, este homem recebeu em sua casa a visita de um naturalista. Enquanto
passeavam pelo jardim, disse o naturalista:
- Esse pássaro aí não é galinha. É uma águia.
- De fato - disse o camponês. É águia. Mas eu a criei como galinha. Ela não é mais uma águia.
Transformou-se em galinha como as outras, apesar das asas de quase três metros de extensão.
- Não - retrucou o naturalista. Ela é e será sempre uma águia. Pois tem um coração de águia.
Este coração a fará um dia voar às alturas.
- Não, não - insistiu o camponês. Ela virou galinha e jamais voará como águia.
Então decidiram fazer uma prova. O naturalista tomou a águia, ergueu-a bem alto e desafiando-
a disse:
- Já que de fato você é uma águia, já que você pertence ao céu e não à terra, então abra suas
asas e voe!
A águia pousou sobre o braço estendido do naturalista. Olhava distraidamente ao redor. Viu as ${ }^{1}$ Depoimento de um adolescente surdo durante sessão de atendimento clínico com a autora deste trabalho.

(C) ETD - Educação Temática Digital, Campinas, v.7, n.2, p.255-265, jun. 2006 - ISSN: 1676-2592. 


\section{DOSSIÊ \\ Grupo de Estudos e Subjetividade}

galinhas lá embaixo, ciscando grãos. E pulou para junto delas.

O camponês comentou:

- Eu lhe disse, ela virou uma simples galinha!

- Não - tornou a insistir o naturalista. Ela é uma águia. E uma águia será sempre uma águia.

Vamos experimentar novamente amanhã.

No dia seguinte, o naturalista subiu com a águia no teto da casa. Sussurrou-lhe:

- Águia, já que você é uma águia, abra suas asas e voe!

Mas quando a águia viu lá embaixo as galinhas, ciscando o chão, pulou e foi para junto delas.

O camponês sorriu e voltou à carga:

- Eu lhe havia dito, ela virou galinha!

- Não - respondeu firmemente o naturalista. Ela é águia, possuirá sempre um coração de águia.

Vamos experimentar ainda uma última vez. Amanhã a farei voar.

No dia seguinte, o naturalista e o camponês levantaram bem cedo. Pegaram a águia, levaram-na para fora da cidade, longe das casas dos homens, no alto de uma montanha. O sol nascente dourava os picos das montanhas.

O naturalista ergueu a águia para o alto e ordenou-lhe:

- Águia, já que você é uma águia, já que você pertence ao céu e não à terra, abra as suas asas e voe!

A águia olhou ao redor. Tremia como se experimentasse nova vida. Mas não voou. Então o naturalista segurou-a firmemente, bem na direção do sol, para que seus olhos pudessem encherse da claridade solar e da vastidão do horizonte.

Nesse momento, ela abriu suas potentes asas, grasnou com o típico kau-kau das águias e ergueu-se soberana, sobre si mesma. E começou a voar, a voar para o alto, a voar cada vez para mais alto. Voou... voou... até confundir-se com o azul do firmamento...”. 


\section{REFERÊNCIAS:}

BÉBIAN, R. A. Essay on the deaf and natural language or introduction to a natural classification of ideas with their proper signs. In LANE, H. E PHILIP, F. The deaf experience: classics in language and education, tradução do original francês para o inglês de Philip, F. Cambridge, Massachusetts e London: Harvard University Press, 1984. (Texto publicado originalmente em francês em 1817).

BERTHIER, F. Les Sourdes-muets avant et depuis l'abbé de l'Epée. In LANE, H. E PHILIP, F. The deaf experience: classics in language and education, tradução do original francês para o inglês de Philip, F. Cambridge, Massachusetts e London: Harvard University Press, 1984. (Texto originalmente publicado em francês em 1840).

BOFF, L. A águia e a galinha: uma metáfora da condição humana. Petrópolis: Vozes, 1997.

DESLOGES, P. A deaf person's observations about na elementary course of education for the deaf. In LANE, H. E PHILIP, F. The deaf experience: classics in language and education, tradução do original francês para o inglês de Philip, F. Cambridge, Massachusetts e London: Harvard University Press, 1984. (Texto publicado originalmente em francês em 1779).

LILIAN CRISTINE RIBEIRO NASCIMENTO Mestre e Doutoranda em Educação Faculdade de Educação da Unicamp E-mail: Icrn05@yahoo.com.br 